OPEN ACCESS

Edited by:

Wengui Yu,

University of California, Irvine,

United States

Reviewed by:

Cyrus Khurshed Dastur,

University of California, Irvine,

United States

Gunjan Parikh,

University of Maryland Medical

System, United States

*Correspondence:

Roy A. Poblete

roy.poblete@med.usc.edu;

roypoblete@gmail.com

Specialty section:

This article was submitted to Neurocritical and Neurohospitalist

Care,

a section of the journal

Frontiers in Neurology

Received: 11 July 2018

Accepted: 24 August 2018 Published: 11 September 2018

Citation: Nguyen PL, Alreshaid L, Poblete RA, Konye G, Marehbian J and Sung $G$

(2018) Targeted Temperature

Management and Multimodality

Monitoring of Comatose Patients After Cardiac Arrest. Front. Neurol. 9:768.

doi: 10.3389/fneur.2018.00768

\section{Targeted Temperature Management and Multimodality Monitoring of Comatose Patients After Cardiac Arrest}

\author{
Peggy L. Nguyen, Laith Alreshaid, Roy A. Poblete*, Geoffrey Konye, Jonathan Marehbian \\ and Gene Sung
}

Department of Neurology, Keck School of Medicine, University of Southern California, Los Angeles, CA, United States

Out-of-hospital cardiac arrest (CA) remains a leading cause of sudden morbidity and mortality; however, outcomes have continued to improve in the era of targeted temperature management (TTM). In this review, we highlight the clinical use of TTM, and provide an updated summary of multimodality monitoring possible in a modern ICU. TTM is neuroprotective for survivors of CA by inhibiting multiple pathophysiologic processes caused by anoxic brain injury, with a final common pathway of neuronal death. Current guidelines recommend the use of TTM for out-of-hospital CA survivors who present with a shockable rhythm. Further studies are being completed to determine the optimal timing, depth and duration of hypothermia to optimize patient outcomes. Although a multidisciplinary approach is necessary in the CA population, neurologists and neurointensivists are central in selecting TTM candidates and guiding patient care and prognostic evaluation. Established prognostic tools include clinal exam, SSEP, EEG and MR imaging, while functional MRI and invasive monitoring is not validated to improve outcomes in CA or aid in prognosis. We recommend that an evidence-based TTM and prognostication algorithm be locally implemented, based on each institution's resources and limitations. Given the high incidence of CA and difficulty in predicting outcomes, further study is urgently needed to determine the utility of more recent multimodality devices and studies.

Keywords: cardiac arrest, targeted temperature management, anoxic brain injury, EEG, prognosis, multimodality monitoring

\section{INTRODUCTION}

Out-of-hospital cardiac arrest (CA) remains a leading cause of sudden morbidity and mortality. Based on recently published statistics from the American Heart Association, 1 of every 7.4 people in the United States will die of sudden cardiac death; however, in those who survive, outcomes have continued to improve over time (1). Enhanced recovery in CA-survivors is likely a product of multifactorial system-based changes, including the advent and evolution of targeted temperature management (TTM).

A multidisciplinary approach is necessary in the care of this complex and critically-ill population. Patients are managed by a team of physicians, nurses and ancillary staff. Neurologists and neurointensivists are often instrumental in the selection of TTM candidates and are central 
to patient care and prognostication. Early consultation with neurologists might increase the use of therapeutic hypothermia (TH) (2). Despite advances in the medical management of out-of-hospital CA, predicting outcomes remains a challenging task. Established prognostic tools have needed to be re-visited with the advent of TTM (3), and the literature has been limited by heterogenous definitions, non-standardized study methods, small sample sizes, and publication bias. We therefore completed this review to highlight the clinical use of TTM, and to provide an updated summary of multi-modality monitoring and prognostication following $\mathrm{CA}$ in a modern neuroscience intensive care unit (ICU). Given the neuroprotective effect of TTM and its impact on prognostication, being familiar with current guidelines and literature is crucial to optimizing patient care.

\section{PATHOPHYSIOLOGY OF ANOXIC INJURY FOLLOWING CARDIAC ARREST}

Hypoxic-ischemic encephalopathy remains a primarily clinical diagnosis; however, the molecular pathophysiology has been studied in both animal and human models. Post-cardiac arrest syndrome, a term used to describe the resuscitative phase that follows return of spontaneous circulation (ROSC), encompasses four key processes: post-CA brain injury, post-CA myocardial dysfunction, systemic ischemia and reperfusion injury and a persistent precipitating pathology (4). Brain injury in the postCA period is thought to be mediated by multiple pathways that result in ischemic injury, impaired cerebral autoregulation, and the development of diffuse cerebral edema (4).

During CA, the brain is exquisitely sensitive to global ischemia. Neuronal injury occurs when the severity and duration of ischemia is sufficient to cause depolarization of the neuronal plasma membrane. In animal models, this has been demonstrated to occur when blood flow falls below $10 \mathrm{~mL} / 100 \mathrm{~g}$ per minute $(5,6)$. Animal studies have also demonstrated that loss of consciousness is experienced as early as $10 \mathrm{~s}$ following circulatory arrest, while an electroencephalogram (EEG) demonstrates isoelectric activity as early as $20 \mathrm{~s}$ after the event (7). When ischemic depolarization is brief with subsequent reperfusion, permanent glial injury may not occur; however, when the depolarization is more prolonged, a cascade of metabolic changes mediated by alterations in adenosine triphosphate (ATP), neurotransmitter pathways, mitochondrial dysfunction and calcium homeostasis occurs, which may lead to irreversible neuronal death. Ischemic depolarization $>30$ min most likely results in neuronal cell death regardless of reperfusion (5).

The exact mechanisms underlying ischemic injury following CA are poorly understood but are likely to involve multiple signaling pathways leading to disruption of cellular homeostasis. At a molecular level, global ischemia causes a depletion of intracellular ATP, with subsequent failure of ATP-dependent ionic channels. This results in accumulation of interstitial potassium with subsequent cell membrane depolarization. The eventual influx of sodium, chloride, and water into cells forms the basis of cytotoxic edema, which occurs during
$\mathrm{CA}$ and other neurologic injuries. In addition, membrane depolarization results in the intracellular accumulation of calcium with activation of voltage gated calcium channels, as well as release of excitatory amino acid transmitters such as glutamate, perpetuating calcium and sodium influx into the neuron $(5,8)$.

If global ischemia occurs without subsequent reperfusion, failure of ATP production will lead to a final common pathway of cellular necrosis. Disruption of calcium homeostasis is thought to be one of the primary mechanisms of neuronal cell injury (9). Accumulation of calcium ions in the mitochondria increases free radical production and mitochondrial permeability transition (MPT), resulting in mitochondrial swelling, oxidative damage, loss of ATP production, and cell death. Cellular accumulation of calcium in the cytosol additionally triggers lipolysis, membrane destabilization, proteolysis, nitric oxide production, and endonuclease DNA degradation $(5,8)$. In vivo measurements of calcium demonstrate that in the acute ischemic period, cytosolic levels increase exponentially within $8 \mathrm{~min}$ of ischemia in vulnerable brain regions, although levels can return to baseline within 30-60 min if reperfusion occurs $(5,10)$.

In the setting of ROSC with cerebral reperfusion, additional ischemic injury can still occur. In particularly vulnerable neuronal subpopulations, including in the cortex, hippocampus, cerebellum, corpus striatum, and thalamus, degeneration can occur over hours to days (4). Secondary neuronal death is also mediated by disruption in calcium homeostasis, as levels of cytosolic calcium have been shown to increase up to $24 \mathrm{~h}$ after the primary insult in susceptible brain regions (5). Additional inflammatory processes involving cytokines are implicated in peripheral tissue ischemia. Cytokines such as interleukin-6 (IL-6) and tumor necrosis factors (TNF) perpetuate delayed ischemia in the reperfusion period. Animal models have demonstrated that rapid infiltration of neutrophil and pro-inflammatory T-lymphocytes into the brain occur as early as $3 \mathrm{~h}$ following ROSC, and last up to 3 days (11).

\section{A PARADIGM SHIFT: TARGETED TEMPERATURE MANAGEMENT IN THE MODERN ICU}

For the last two decades, TTM, previously referred to as therapeutic hypothermia, has been a growing research topic in the ICU literature. Currently, given its neuroprotective role after CA with improvement of neurologic outcomes, TTM is considered the standard of care for survivors of CA who present with coma after ROSC (12).

\section{Mechanisms of Neuroprotection With Hypothermia}

The manner that hypothermia acts as a neuroprotectant is still not fully understood. In animal models, hypothermia has been shown to limit several microscopic events, including the inhibition of inflammatory cytokine release (ex. interleukins, prostaglandins), that normally lead to apoptosis and cell death 
(13-15). At a tissue level, hypothermia was found to reduce cerebral metabolic demand (approximately $6-8 \%$ per $1^{\circ} \mathrm{C}$ ), cerebral edema, and intracranial pressure (ICP), while also increasing seizure threshold (16).

\section{Targeted Temperature Management}

TTM was first introduced in the 1950s and 1960s, primarily in animal models. Many of these early studies showed that both moderate systemic hypothermia $\left(32-30^{\circ} \mathrm{C}\right)(17)$ and mild hypothermia $\left(34^{\circ} \mathrm{C}\right)(18-20)$ cause decreased brain damage after $\mathrm{CA}$ in animals. The subject of TH somewhat faded until it was reintroduced in human subjects in the early 2000s by two important randomized trials (RCTs): a study by Bernard et al, and the Hypothermia after Cardiac Arrest Study Group (21, 22). These studies were the first to provide Class I evidence supporting the use of TTM for CA survivors to improve both survival and functional outcomes using mild hypothermia $\left(32^{\circ}-34^{\circ} \mathrm{C}\right.$ for 12 or $24 \mathrm{~h}$ ). Based on these findings, the International Liaison Committee on Resuscitation (ILCOR) recommended in 2003 that CA-survivors in coma should receive $\mathrm{TH}$ when the initial rhythm was ventricular fibrillation, with potential benefit with other rhythms (23).

These recommendations have since been under continuous review and change. Three major clinical trials and a meta-analysis by Kim et al failed to show definite improvement in outcomes in patients with non-shockable rhythm (24-27). Similarly, TTM does not appear to benefit patients who sustain in-hospital CA in terms of mortality or neurologic recovery (28). Regarding the timing and duration of TTM and depth of TH, best practices are unknown. Pre-hospital initiation of TTM has not been shown to improve outcomes $(29,30)$. Prolonged cooling also appears to have no important clinical effect. Kirkegaard et al compared 24 vs. $48 \mathrm{~h}$ of cooling to $33^{\circ} \mathrm{C}$ and found no significant differences in neurologic outcomes (31). While early guidelines recommend mild hypothermia, a recent RCT found no change in neurologic recovery or survival at 6 months when comparing $33^{\circ}$ and $36^{\circ} \mathrm{C}$ (32).

Current guidelines do not recommend a specific cooling method for TTM; however, multiple methods are available for induction and maintenance, including both invasive and noninvasive devices $(33,34)$. Recent data suggest that endovascular cooling is more rapid and may be more effective in maintaining TTM, although surface cooling may be as effective during induction $(35,36)$; however, clinical trials to-date have not shown effect on overall mortality and neuro-sequelae between invasive and non-invasive methods. Alternative devices, including transnasal, peritoneal and esophageal cooling are under investigation, but no recommendations for their use can be made currently (37-39).

The current American Heart Association, Canadian TTM guidelines, and American Academy of Neurology practice parameters are considered the most evidence-based clinical recommendations and the standard of care for managing postCA patients who remain in coma after $\operatorname{ROSC}(12,40,41)$ (Table 1). Further research is needed to study different aspects of these guidelines to achieve the best clinical results.

TABLE 1 | Summary of recent guidelines on targeted temperature management for out-of-hospital cardiac arrest patients.

Committee Summary of recommendations

2015 American Heart Association (12)

2016 Joint Statement from The Canadian Association of Emergency Physicians, the Canadian Critical Care Society, Canadian Neurocritical Care Society, and the Canadian Critical Care Trials Group (40)

2017 American Academy of Neurology Practice Guidelines (41)
- Induce hypothermia for unconscious adult patients with ROSC after OHCA when the initial rhythm was VF or pVT (class I, level of evidence: B-R)

- Similar therapy may be beneficial for patients with non-VF/non-pVT (non-shockable) OHCA or with inhospital arrest (class I, level of evidence: C-EO)

- The temperature should be maintained between $32^{\circ}$ $36^{\circ} \mathrm{C}$ (class I, level of evidence: B-R)

- It is reasonable to maintain TTM for at least $24 \mathrm{~h}$ (class Ila, level of evidence: C-EO)

- Routine prehospital cooling of patients with ROSC with IV rapid infusion is not advised (class III: no benefit; level of evidence A)

- It is reasonable to prevent fever in comatose patients after TTM (class Ilb, level of evidence C-LD)

- Hemodynamically stable patients with spontaneous mild hypothermia $\left(>33^{\circ} \mathrm{C}\right)$ after resuscitation from cardiac arrest should not be actively rewarmed

- We recommend that patients who suffer outof-hospital cardiac arrest are eligible for TTM (High quality, strong recommendation)

- We recommend that TTM can be initiated in any medical environment with the necessary supports, including prehospital, ED and critical care unit (Moderate quality, strong recommendation)

- We recommend that clinicians attempt to achieve target temperature as rapidly as possible (Low quality but strong recommendation)

- We do not recommend a specific cooling method for TTM."

- We recommend that patients undergoing TTM should receive sedation and analgesia

- We suggest that paralytics be used during induction and rewarming phases of TTM, to facilitate tight temperature control and to prevent shivering

- Comatose patients after CA in whom the initial cardiac rhythm is VT or VF, TH is likely effective in improving neurologic outcome and survival (Level A)

- Comatose patients after CA in whom the initial cardiac rhythm is VTNF or PEA/asystole should not be offered prehospital cooling with 2 liters $4^{\circ} \mathrm{C}$ IV fluid or intranasal cooling (Level A)

- Comatose patients after CA in whom the initial cardiac rhythm is either VTNF or PEA/asystole, TTM $\left(33^{\circ} \mathrm{C}\right.$ for $24 \mathrm{~h}$ followed by $8 \mathrm{~h}$ of rewarming to $37^{\circ} \mathrm{C}$ and maintained below $37.5^{\circ} \mathrm{C}$ until $72 \mathrm{~h}$ ) is likely as effective as $\mathrm{TH}$ in improving neurologic outcome and survival and is an acceptable alternative to TH (Level B)

- In comatose patients after CA, the addition of coenzyme Q10 to TH possibly improves survival but does not improve neurologic status at 3 months and may be offered (Level C)

- No recommendations are made on the following (Level U):

TH when the initial cardiac rhythm is PEAvasystole Use of $32^{\circ}$ vs. $34^{\circ} \mathrm{C} \mathrm{TH}$

Use of invasive cooling instead of surface cooling Use of standardized protocols for $\mathrm{TH}$ Use of epoeitin alfa in addition to mild $\mathrm{TH}$

ROSC, return of spontaneous circulation; OHCA, out-of-hospital cardiac arrest; VF ventricular fibrillation; $p V T$, pulseless ventricular tachycardia; $I V$, intravenous; TTM, targeted temperature management; $R$, randomized; $E O$, expert opinion; $L D$, limited data; VT, ventricular tachycardia; TH, therapeutic hypothermia; PEA, pulseless electrical activity; $\mathrm{I}$, intravenous. 


\section{NEUROPHYSIOLOGIC TESTING AFTER CARDIAC ARREST}

\section{Use of EEG Studies}

Beyond the clinical exam, EEG is one of the most widely used prognostic tools after anoxic brain injury from CA. Areas most susceptible to hypoxic-ischemic injury, including the cerebral cortex and hippocampus (42) are highly epileptogenic and are feasibly captured by surface EEG. From a practical aspect, it is an attractive study because it is non-invasive, can be performed rapidly, and is available at most hospitals managing CA patients. Clinical seizures are reported from TTM trials to occur in over $25 \%$ of patients (32), while malignant EEG features are recorded in up to $86 \%$ of patients who remain comatose after resuscitation and re-warming (43). Non-convulsive seizures are thought to occur in approximately one-quarter of comatose patients after cardiac arrest $(44,45)$.

\section{Timing and Duration of EEG}

The optimal timing for EEG recording after CA is unknown. Since sedation is required for TH and TTM, EEG is often reserved for those who fail to awake after rewarming; however, early monitoring may be indicated. In study populations undergoing TTM, most seizures on continuous EEG (cEEG) occur within $12 \mathrm{~h}$ of resuscitation and prior to achieving normothermia (44, 45). Malignant patterns in the first $8 \mathrm{~h}$ of cEEG have also demonstrated a high positive predictive value for poor outcome (46). Although this suggests utility in early cEEG, studies have shown that intermittent short-duration EEG has potentially similar diagnostic and prognostic yield, with no difference in clinical outcomes, and is associated with reduced per patient cost $(47,48)$. Given the lack of evidence to suggest treatment of seizures and malignant EEG findings improves outcomes $(49,50)$, the principal use of intermittent EEG as a prognostic tool is reasonable in centers where cEEG is not readily available.

\section{Prognostic Value of EEG Findings}

Electroencephalogram findings most thought to predict poor neurologic outcome includes absence of EEG reactivity, alpha coma, low-voltage recording, burst-suppression pattern, and status epilepticus (49). Several older and newer grading scales that account for TTM have been proposed to classify EEG findings after CA (50-54); however, none have achieved widespread adoption. This may in part be due to a difficulty of interpreting and understanding the clinical implications of complex EEG findings for non-electroencephalographers. A simplified system might differentiate between "benign" and “malignant” EEG patterns $(43,55)$.

\section{EEG features in patients who do not undergo therapeutic hypothermia}

A low-voltage EEG $(\leq 21 \mu \mathrm{V})$ reflects neuronal dysfunction and is a reliable predictor of poor outcome in those who do not receive TTM. In two larger studies, low-voltage EEG seen at 24$72 \mathrm{~h}$ after resuscitation was associated with poor outcome with a $0 \%$ false positive rate (FPR) $(56,57)$. Similarly, myoclonic status epilepticus (MSE) when differentiated from a benign form of chronic myoclonus, Lance-Adams syndrome, has been invariably associated with poor outcome in those who are not treated with TH (58). Although electrographic seizure other than MSE, alpha coma and burst suppression are considered useful prognostic findings, they are not invariably associated with poor outcome in the CA population $(53,57,59,60)$.

\section{EEG features in patients treated with therapeutic hypothermia.}

TTM improves neurologic outcomes following CA (32) but lowering intracranial temperature and the sedation necessary for $\mathrm{TH}$ confounds EEG interpretation. Its accuracy as a prognostic tool has had to be re-evaluated with the advent of TTM. Although early post-hypoxic myoclonus is associated with poor prognosis, since the publication of the 2006 American Academy of Neurology Guidelines on prognostication following CA (61), several authors have reported outcomes better than predicted in patients with myoclonic seizures (44, 50, 62-65). Cortical myoclonus or status myoclonus within $72 \mathrm{~h}$ from CA did not exclude a good neurologic recovery defined as Cerebral Performance Category (CPC) 1 or 2, with a 5\% FPR (44, 50, 62-64). Some have suggested that "benign" and "malignant" myoclonus or MSE can be differentiated by the background EEG pattern $(65,66)$.

Status epilepticus (SE) other than MSE strongly predicts poor outcome (CPC 3-5) (45, 50, 67); however, good outcome in CA patients is possible. In one study of 106 comatose CA survivors, 2/33 SE patients achieved good neurologic outcomes (66). Like MSE, EEG background is an important factor. In a study of cEEG in TTM patients, those with SE arising from burstsuppression invariably had poor neurologic recovery, while good outcomes were possible in those with SE arising from an EEG with continuous background (4\% FPR) (68).

A burst-suppression EEG background or low-amplitude recording alone does not predict poor outcome with $100 \%$ specificity $(64,68,69)$. Similarly, a non-reactive EEG background is compatible with neurologic recovery with a $3 \%$ FPR when recorded during $\mathrm{TH}(50,62,67)$, while in one larger study, three patients with absence of EEG reactivity within $72 \mathrm{~h}$ of resuscitation achieved good outcomes (63). Although prognosis is not invariably poor in patients undergoing TTM with a single malignant EEG feature, the presence of multiple features significantly increases the likelihood of poor outcome. In a large cohort of patients enrolled in a TTM trial, a single malignant EEG feature had a low specificity for poor prognosis (48\%), which increased to a $96 \%$ positive predictive value when two malignant EEG features were present (43).

\section{Continuous EEG Using Depth Electrodes}

In neurocritical care, EEG depth electrodes are inserted through small burr holes, often in combination with other multimodality brain monitors to capture electrographic activity below the cortex. Their use in the management and prognosis of CA survivors has not been extensively studied in any large trial. In one case report, authors demonstrated the feasibility of using multimodality monitoring, including depth EEG, to detect SE that was associated with reductions in brain tissue oxygen tension 
and increase in cerebral blood flow and brain temperature (70). Future study is needed if invasive monitoring that includes depth EEG has additional prognostic value in CA.

\section{Limitations}

Beyond being confounded by hypothermia and sedative medications, EEG for prognostication after CA has other important limitations. The frequency of EEG and availability of cEEG is dependent on institutional resources and varies widely, with cEEG often only available at larger academic centers. Given the lack of evidence suggesting its superiority to intermittent EEG $(49,50)$, the American Clinical Neurophysiology Society and other committees have not made guidelines to standardize EEG after CA $(71,72)$.

EEG interpretation remains a specialized skill, with the large proportion of ICU providers unable to independently interpret studies. Recordings and terminology can be confusing to nonepileptologists. Even among experts, interrater agreement on EEG patterns can vary (73), resulting in many authors proposing standardization to classifying EEG in this population $(43,73)$. Use of automated, quantitative EEG techniques may find future utility in prognostication and is the subject of current study $(51,74,75)$.

\section{Somatosensory Evoked Potentials}

Somatosensory Evoked Potentials (SSEPs) are often used for prognostication in CA survivors who have a poor neurologic exam after resuscitation and normothermia (76). In the most widely used test, small electrical stimulation $(<50 \mu \mathrm{V})$ is applied to the median nerve in the arm, followed by recording of poststimuli waveforms over the primary somatosensory cortex by surface electrodes (76). The bilateral absence of the short-latency N20 waveform is highly specific for poor outcome after CA. In those who are not treated with $\mathrm{TH}$, bilateral absence of the N20 response within the first 7 days showed a 0\% FPR (95\% CI 0-12] with only $1 / 432$ patients achieving a good outcome (58). In TTM patients, this finding also showed high predictive value for poor outcome both during $\mathrm{TH}(64,77,78)$ and after rewarming $(62$, $64,67,77,78)$, with exception of one case where reappearance of the N20 response corresponded with full neurologic recovery (79). Given these robust findings, early use of short-latency N20 SSEPs for prognostication after CA is endorsed by multiple expert committees $(64,72)$. The use of longer latency waveforms, such as the N70 response (80), requires further study.

\section{Limitations}

The optimal timing for SSEP is unknown. Given both peripheral and central conduction times are prolonged during hypothermia (81), most practitioners delay SSEP testing until after the rewarming phase. Using a dichotomous measure of absent vs. present SSEP also significantly limits its sensitivity in predicting poor outcomes. Determining prognostically useful N20 amplitude thresholds should be further studied in future cohorts (82). Importantly, SSEPs are not routinely performed at all hospitals that treat CA survivors, further limiting its adoption in standardized prognostication algorithms.

\section{IMAGING MODALITIES AFTER CARDIAC ARREST \\ CT Imaging}

Brain CT is typically the first neuroimaging study obtained in out-of-hospital CA survivors, as it can be performed quickly and identifies patients who may not benefit from TTM. The primary finding in moderate to severe hypoxic-ischemic injury is cerebral edema characterized by attenuation of affected gray and white matter (83). In a study of TTM trial patients, generalized edema was seen in $9.6 \%$ of CT images within $24 \mathrm{~h}$ of ROSC and predicted poor outcome (CPC 3-5) with $97.6 \%$ specificity (95\% CI $91.8-$ 9.4) but only $14.4 \%$ sensitivity (95\% CI 9.4-21.4) (84). Between days 1 and 7, generalized cerebral edema predicted poor outcome with a $0 \%$ FPR. In this study, other CT findings were infarct in $18.9 \%$ and intracranial hemorrhage in $6.3 \%$ (84).

\section{The Role of Standard MRI}

Despite MRI being more sensitive for detecting neuronal injury compared to CT, because of longer acquisition times and more necessary resources, its early use during the pre- $\mathrm{TH}$ and $\mathrm{TH}$ phase is limited. The optimal time window for MRI imaging is unknown; however, prognostic accuracy may be greatest between 2 and 5 days, with reduced sensitivity if done within $24 \mathrm{~h}(85,86)$.

Brain areas most susceptible to hypoxic-anoxic injury include the cerebral cortex and deep brain nuclei that include the caudate, basal ganglia and thalamus. Diffusion restriction involving these areas, characterized by hyperintensity on diffusion-weighted imaging (DWI) and hypointensity on apparent diffusion coefficient (ADC) images, predicts poor outcome with high specificity $(85,87,88)$. In a study correlating MRI findings with neuron-specific enolase, a biomarker with high prognostic value, levels $>33 \mu \mathrm{g} / \mathrm{ml}$ after CA was associated with extensive DWI changes in both deep nuclei and the cortex (89). These patients had invariably poor outcome. More recently, quantitative measures of diffusion restriction burden on MRI has been proposed to standardize post-CA prognostication $(86,87$, 90, 91); however, the most appropriate thresholds have not been established. In one multi-centered study, an $\mathrm{ADC}$ value $<650$ $\times 10^{-6} \mathrm{~m}^{2} / \mathrm{s}$ in $\geq 10 \%$ of the total brain volume independently predicted poor outcome with a specificity of $91 \%$ (95\% CI 7598 ) and sensitivity of $72 \%$ (95\% CI $61-80$ ), with $>22 \%$ of brain volume needed to achieve $100 \%$ specificity (90). In another study, $<15 \%$ total brain volume with significant diffusion restriction was predictive of good neurologic recovery (91). As part of multimodality monitoring, combining MRI findings with EEG features, biomarkers and clinical exam may result in the highest accuracy in predicting outcomes $(89,91)$. Currently, the implementation of MRI in post-CA prognostication algorithms has not been strongly recommended by consensus guidelines (72).

\section{Other Imaging Modalities}

\section{Functional Imaging}

There are a limited number of studies with small sample sizes that have investigated the use of functional MR imaging (fMRI) in the management and prognosis of CA survivors (92). In a positron 
emission tomography (PET) pilot study of 7 post-CA patients, all initially demonstrated a low cerebral metabolic rate of oxygen metabolism (CMR02) and cerebral blood flow; however, at day 7, those with persistent coma had lower CMR02 compared to those who regained consciousness (93). More recently, fMRI connectome imaging has demonstrated potential as a prognostic tool in CA, where patients who achieved favorable outcome have higher default-mode network connectivity $(94,95)$. It is unclear if $\mathrm{fMRI}$ is more accurate in predicting outcome in comparison to other MRI modalities (94), and they have not been compared directly with more established prognostic tools (92). Validation of PET imaging and other fMRI techniques may be a field of future research.

\section{Transcranial Doppler Ultrasound}

Transcranial Doppler ultrasound (TCD) is a useful bedside, non-invasive tool for monitoring characteristics in cerebral blood flow and intracranial vascular resistance. Early TCD studies suggested that higher vascular resistance indices and post-resuscitation hyperemia predicted poor outcome $(96,97)$; however, subsequent larger studies have not found correlation between TCD measurements and outcomes during both the TH phase and after rewarming $(98,99)$. TCDs in CA survivors is not part of routine practice in most hospital centers.

\section{OTHER MULTIMODALITY MONITORING OF COMATOSE PATIENTS AFTER CARDIAC ARREST}

\section{Use of Invasive and Noninvasive Multimodality Monitors}

Following CA, global anoxia leads to derangements of cerebral oxygenation and metabolism. Multimodality monitoring, including invasive ICP monitors, microdialysis catheters, jugular bulb catheters, near-infrared spectroscopy (NIRS) and monitors of brain oxygen tension, discussed here, aim to provide the clinician with physiologic parameters that reflect cerebral perfusion, tissue oxygenation and degree of metabolic derangement to help guide treatment and minimize secondary brain injury. Its use in other forms of neurologic injury, including traumatic brain injury and subarachnoid hemorrhage, have been studied extensively, but its use in survivors of CA remains poorly established in clinical practice.

\section{Brain Oxygen Tension Monitors}

Direct measurement of brain oxygen tension (PtiO2) or brain tissue oxygenation (PbtO2) is performed using a catheter similar in size to an ICP monitor, often through a burr hole or craniotomy site. Currently, it is primarily utilized in traumatic brain injury (TBI) populations, where studies have demonstrated its use may help guide treatment; however, the evidence for $\mathrm{PbtO} 2$ monitoring improving outcomes is inconsistent and its recommendation was removed from the most recent Brain Trauma Foundation Guidelines (100). PbtO2 monitors have the disadvantage of being limited to measuring focal ischemia, which may not be adequate in CA patients, and requiring daily calibration (101).

In animal models, mostly porcine, brain tissue oxygenation has been measured during $\mathrm{CA}$ and cardiopulmonary resuscitation (CPR). In one model, $\mathrm{PbtO} 2$ decreased to near zero during arrest, but increased with initiation of $\mathrm{CPR}$ and, if ROSC was achieved, exceeded pre-arrest values by 4-fold (102). Similar findings were seen in another animal model, although $\mathrm{PbtO} 2$ did not increase during $\mathrm{CPR}$ and only recovered with achievement of ROSC (103). In a recent porcine model of CA, hemodynamic-directed CPR was compared to depth-targeted CPR. In the study, a higher PbtO2 was achieved with hemodynamic-directed care that utilized vasopressors to maintain a target coronary perfusion pressure $>20 \mathrm{mmHg}$ (104). In humans, one case report demonstrated that feasibility of $\mathrm{PbtO} 2$ monitoring during $\mathrm{CPR}$ in an adult patient who achieved ROSC (105). Theoretically, $\mathrm{PbtO} 2$ monitoring would provide accurate and real-time measurements of brain oxygenation to ensure cerebral perfusion is maintained during CPR, ROSC, and TTM. Larger case series and trials are needed.

\section{Near-Infrared Spectroscopy}

NIRS is a non-invasive method of monitoring regional oxygenation in the cerebral cortex $\left(\mathrm{rSO}_{2}\right)$. Near-infrared light emitted by one surface probe passing through the cortex is absorbed by biological molecules including oxyhemoglobin, deoxyhemoglobin, and less commonly cytochrome-c oxidase (CCO), at different wavelengths. Differences in absorption by the receiving probe are used to quantifythe proportion of oxygenated hemoglobin or other molecule, which is reflective of perfusion (101). Advantages of NIRS are that it is non-invasive and can be performed at bedside.

Higher values of $\mathrm{rSO}_{2}$ on NIRS have been demonstrated in patients achieving ROSC compared to those who do not achieve ROSC (106). Studies have also demonstrated higher values of $\mathrm{rSO}_{2}$ using NIRS in post-CA patients with good neurologic outcome, although specific thresholds or cut-offs have not been established. In one study, post-CA patients with good neurologic outcome had higher $\mathrm{rSO}_{2}$ values compared to those who with poor outcome $(55.6 \pm 20.8 \%$ vs. $19.7 \pm 11.0 \%, p<$ 0.001 , respectively), with a threshold $\mathrm{rSO}_{2}$ value of $>42 \%$ for predicting good outcome yielding a sensitivity of 0.79 , specificity of 0.95, PPV 0.41 and NPV 0.99 (107). In comparison, another prospective study found that although post-CA patients with a good outcome had significantly higher median $\mathrm{rSO}_{2}$ levels compared to those who had poor outcome (median $\mathrm{rSO}_{2}$ of $68 \%$ vs. median $\mathrm{rSO}_{2}$ of $58 \%$, respectively) there was significant overlap in the range of $\mathrm{rSO}_{2}$ between the two groups, limiting its use as a prognostic tool (108).

\section{Microdialysis Catheters}

Microdialysis catheters allow frequent assessments of cerebral metabolism and ischemic injury by utilizing a thin dialysis probe that is inserted into brain interstitial tissue. The catheter can measure extracellular solutes that diffuse through the membrane of the probe. Measurable solutes include markers of cerebral metabolism such as CSF lactate, pyruvate, glucose, and markers 
of excitotoxicity such as glutamate, and cellular damage such as glycerol $(109,110)$. Additional values of importance, including markers of metabolic crisis such as lactate:pyruvate ratio (LPR), can be calculated autonomously.

During CA, the brain becomes oligemic, leading to diffuse ischemia. Patterns of ischemia are characterized by a decrease in cerebral glucose and an increase in cerebral lactate, which may reflect a state of anaerobic metabolism. These findings, along with increased glutamate and LPR have been demonstrated in animal models of CA $(111,112)$. Microdialysis results may have additional prognostic value. In rats, survivors of CA after CPR showed significantly higher cerebral lactate and glucose concentrations within 8 min compared to non-survivors, as well as increased lactate, glucose and pyruvate beyond $8 \mathrm{~min}$ (111). One small patient series of 4 human subjects with microdialysis catheters who underwent TTM demonstrated elevated LPRs that persisted despite achieving a neurologically intact exam (113). Although glutamate was initially high, values normalized in all 4 patients. Another patient series of CA survivors who underwent TTM found that LPRs progressively increased in those with poor outcomes with significantly higher values on days 2-3 compared to patients with favorable outcomes (114).

These preliminary studies establish the feasibility of microdialysis catheter monitoring in CA patients undergoing TTM. Although it has been demonstrated that neurochemical markers of cerebral ischemia are found after CA, further studies are needed to determine if they have a role in predicting outcome.

\section{Jugular Bulb Catheters}

Indirect measurements of cerebral oxygenation using jugular bulb catheters have been used in brain injured patients to assess the balance of cerebral oxygen supply and consumption, and to estimate cerebral perfusion (101). The catheters are placed in the internal jugular vein and are directed cranially to measure venous oxygen saturation (SjvO2], with a normal range of $55-70 \%$. In $\mathrm{CA}, \mathrm{SjvO} 2$ is reduced, reflecting decreased oxygen delivery and increased oxygen utilization in a stress state (101). Disadvantages of jugular bulb catheters are that it is an invasive monitor, with risk of carotid puncture, hematoma formation, or venous thrombosis during prolonged monitoring (101).

In a study of 30 comatose post-resuscitation patients, all subjects had an initial SjvO2 that was lower than the measured mixed venous oxygen saturation $(\mathrm{SmvO} 2)$ within $6 \mathrm{~h}$ of $\mathrm{CA}$, but in 12/20 non-survivors, $\mathrm{SjvO} 2$ increased significantly to values higher than the SmvO2 (115). The significance of this finding is unclear. Other studies have demonstrated higher $\mathrm{SjvO} 2$ in comatose non-survivors of $\mathrm{CA}$, which was thought to reflect a decrease in cerebral oxygen consumption due to loss of functional brain tissue and may be an indicator of poor neurologic outcome (116). Although it involved a small sample size, the study found that the positive predictive value of a difference between $\mathrm{SmvO} 2$ and $\mathrm{SjO} 2$ of $\leq 0$ for predicting irreversible brain damage at $24 \mathrm{~h}$ following CA was $93 \%$, while the negative predictive value of $\mathrm{SmvO} 2-\mathrm{SjO} 2>0$ was $53 \%$. Another study of 34 patients found that having a SmvO2 $>\mathrm{SjvO} 2$ between 24 and $48 \mathrm{~h}$ after ROSC had a positive predictive value of $100 \%$ and a negative predictive value of $92 \%$ for predicting recovery of consciousness (117). Unfortunately, these results have not been reliably duplicated with TTM patients. In the TTM era, one study of 75 patients found no difference in SjvO2 between patients with good and poor outcome at 6 months (118).

\section{External Ventricular Drain and ICP Catheters}

ICP monitoring devices are typically categorized based on their location of placement, often either ventricular or intraparenchymal, with extradural and subdural monitors being less common. Intraventricular catheters are both diagnostic and therapeutic, allowing clinicians to drain cerebrospinal fluid if ICP rises. Intraparenchymal monitors have the advantage of lower infection rates compared to ventricular catheters; however, they are more prone to drift and technical complications that limit its usability (119).

Following CA, cerebral edema occurs as early as the first $24 \mathrm{~h}$, with CT imaging demonstrating diffuse loss of graywhite differentiation in up to $12 \%$ of scans performed and global cerebral edema in as many as 6\% (120). ICP monitoring is frequently used when cerebral edema is diagnosed in brain injured patients, including those with traumatic brain injury, intracerebral hemorrhage, or subarachnoid hemorrhage. Uncontrolled intracranial hypertension is associated with poor outcomes in the TBI literature, and although its impact in CA patients is not well defined, ICP elevations can result in cerebral herniation and may serve as a trigger for monitoring and augmenting cerebral perfusion pressures (CPP) (8).

Elevations in ICP have been identified in post-CA patients during the resuscitation period, which may be due to delayed hyperemia (97). In one post-resuscitation study of ICP monitoring performed on 84 patients, peak ICP $>25 \mathrm{mmHg}$ was associated with poor outcomes. Additionally, non-survivors consistently had higher ICPs and lower CPP than survivors (121). This association has been noted in more recent studies following the advent of TTM. Increases in ICP have been noted during both $\mathrm{TH}$ and the rewarming period, and at least in one study, all cases of ICP $>25 \mathrm{mmHg}$ were associated with mortality $(113,122)$. Even when CPP did not differ between groups, studies have shown elevated ICPs are associated with poor outcome (114). The evidence suggests that elevated ICP can occur after CA and during rewarming in patients who undergo TTM; although, to date, no large studies have used ICP monitors to guide management of the post-CA patient.

\section{DISCUSSING PROGNOSIS AFTER CARDIAC ARREST}

Despite the use of multiple prognostic tools, prediction of outcomes after CA is difficult. Registries such as the International Cardiac Arrest Registry (INTCAR), a prospective multinational registry of treatment and outcomes in post-CA patients who achieve ROSC, have been developed with the intention of furthering research on CA outcomes (123). The ongoing clinical trial, Multimodal Outcome Characterization in Comatose Cardiac Arrest Patients Registry and Tissue Repository 
(MOCHA), proposes to develop a multimodal prediction model for outcomes in post-CA patients (124). Currently, given the available evidence in the literature, it is reasonable to discuss pertinent clinical exam, EEG, SSEP, biomarker, and CT and MRI findings with family members and surrogate decision makers to help guide their expectations and inform their decisions. Further validation is needed before fMRI and invasive multimodality monitoring devices are used in standardized prognostication algorithms.

The timing of outcome prediction is crucial in CA. The $72 \mathrm{~h}$ clinical exam remains the most informative; however, in patients receiving TTM, the earliest time for prognostication using the clinical exam may be $72 \mathrm{~h}$ after achieving normothermia and after other confounding factors, such as paralysis and sedation are safely excluded $(12,64)$. Similarly, the accuracy of other prognostic tools may be affected by $\mathrm{TH}$, with MRI at day $2-5$ being reasonable for prognostication $(85,86)$.

The accuracy and limitations of prognostication should be shared with all family members and decision makers. Caution must be taken to avoid propagation of a self-fulfilling prophecy in withdrawing life sustaining therapy in this patient population. Studies on prognostication post-CA may suffer from bias as patients with poor neurologic prognosticators may receive limited intensive care or may have had recommendations for withdrawal of treatment (125). Often, goals of care established by family members or decision makers do not align with a patient's prognosis (126), where patient age, comorbidities, prior patient

\section{REFERENCES}

1. Benjamin EJ, Virani SS, Callaway CW, Chang AR, Cheng S, Chiuve SE, et al. Heart disease and stroke statistics--2018 update: a report from the american heart association. Circulation (2018) 137:e67-492. doi: 10.1161/CIR.0000000000000558

2. Guterman EL, Kim AS, Josephson SA. Neurologic consultation and use of therapeutic hypothermia for cardiac arrest. Resuscitation (2017) 118:43-8. doi: 10.1016/j.resuscitation.2017.06.025

3. Samaniego EA, Persoon S, Wijman CAC. Prognosis after cardiac arrest and hypothermia: a new paradigm. Curr Neurol Neurosci Rep. (2011) 11:11-119. doi: 10.1007/s11910-010-0148-9

4. Neumar RW, Nolan JP, Adrie C, Aibiki M, Berg RA, Böttiger BW, et al. Post-cardiac arrest syndrome: epidemiology, pathophysiology, treatment, and prognostication. A consensus statement from the International Liaison Committee on Resuscitation (American Heart Association, Australian and New Zealand Council on Resuscitation, European Resuscitation Council, Heart and Stroke Foundation of Canada, InterAmerican Heart Foundation, Resuscitation Council of Asia, and the Resuscitation Council of Southern Africa); the American Heart Association Emergency Cardiovascular Care Committee; the Council on Cardiovascular Surgery and Anesthesia; the Council on Cardiopulmonary, Perioperative, and Critical Care; the Council on Clinical Cardiology; and the Stroke Council. Circulation (2008) 118:245283. doi: 10.1161/CIRCULATIONAHA.108.190652

5. Neumar RW. Molecular mechanisms of ischemic neuronal injury. Ann Emerg Med. (2000) 36:483-506. doi: 10.1067/mem.2000. 110995

6. Symon L. Flow thresholds in brain ischaemia and the effects of drugs. $\mathrm{Br} J$ Anaesth. (1985) 57:34-43. doi: 10.1093/bja/57.1.34

7. Hossmann KA, Grosse Ophoff B. Recovery of monkey brain after prolonged ischemia. I. Electrophysiology and brain electrolytes. J Cereb Blood Flow Metab. (1986) 6:15-21. doi: 10.1038/jcbfm.1986.3 wishes, and cultural aspects factor in to a decision. Establishing and implementing a protocol and expected practice, based on each institution's resources and limitations may help clinicians and families navigate this difficult course.

\section{CONCLUSION}

Neurologists and neurointensivists are central to guiding TTM, ICU care and prognostication in survivors of CA. Given the neuroprotective effects of TTM and their influence on prognostication and multimodality monitoring, providers should be familiar with the most recent guidelines and literature. We recommend that an evidence-based TTM and prognostication algorithm be locally implemented, based on each institution's resources and limitations. Given the high incidence of CA and the difficulty in predicting outcomes, further study is urgently needed to determine the utility of more recent multimodality devices and studies.

\section{AUTHOR CONTRIBUTIONS}

RP, JM, and GS conceived the manuscript topic and outline. PN, LA, RP, and GK were the primary authors of the manuscript with input from all authors. PN, RP, and JM were involved in critical manuscript revisions. RP, JM, and GS directed manuscript preparation. All authors read and approved the submitted version.
8. Reis C, Akyol O, Araujo C, Huang L, Enkhjargal B, Malaguit J, et al. Pathophysiology and the monitoring methods for cardiac arrest associated brain injury. Int J Mol Sci. (2017) 18:E129. doi: 10.3390/ijms18010129

9. Deshpande JK, Siesjö BK, Wieloch T. Calcium accumulation and neuronal damage in the rat hippocampus following cerebral ischemia. J Cereb Blood Flow Metab. (1987) 7:89-95.

10. Erecinska M, Silver IA. Relationship between ions and energy metabolism: cerebral calcium movements during ischaemia and subsequent recovery. Can J Physiol Pharmacol. (1992) 70(Suppl.):S190-3.

11. Deng G, Carter J, Traystman RJ, Wagner DH, Herson PS. Pro-inflammatory T-lymphocytes rapidly infiltrate into the brain and contribute to neuronal injury following cardiac arrest and cardiopulmonary resuscitation. J Neuroimmunol. (2014) 274:132-40. doi: 10.1016/j.jneuroim.2014.07.009

12. Callaway CW, Donnino MW, Fink EL, Geocadin RG, Golan E, Kern $\mathrm{KB}$, et al. Part 8: post-cardiac arrest care: 2015 American Heart Association guidelines update for cardiopulmonary resuscitation and emergency cardiovascular care. Circulation (2015) 132(Suppl. 2):S465-82 doi: 10.1161/CIR.0000000000000262

13. Scott BD, Hogue T, Fixley MS, Adamson PB. Induced hypothermia following out-of-hospital cardiac arrest; initial experience in a community hospital. Clin Cardiol. (2006) 29:525-29. doi: 10.1002/clc.23

14. Alam HB, Bowyer MW, Koustova E, Gushchin V, Anderson D, Stanton K, et al. Learning and memory is preserved after induced asanguineous hyperkalemic hypothermic arrest in a swine model of traumatic exsanguination. Surgery (2002) 132:278-88. doi: 10.1067/msy.2002.125787

15. Weng Y, Sun S. Therapeutic hypothermia after cardiac arrest in adults: mechanism of neuroprotection, phases of hypothermia, and methods of cooling. Crit Care Clin. (2012) 28:231-43. doi: 10.1016/j.ccc.2011. 10.012

16. Sekhon MS, Ainslie PN, Griesdale DE. Clinical pathophysiology of hypoxic ischemic brain injury after cardiac arrest: a "two-hit" model. Crit Care (2017) 21:90. doi: 10.1186/s13054-017-1670-9 
17. Leonov Y, Sterz F, Safar P, Radovsky A. Moderate hypothermia after cardiac arrest of 17 minutes in dogs: effect on cerebral and cardiac outcome. Stroke (1990) 21:1600-06. doi: 10.1161/01.STR.21.11.1600

18. Kuboyama K, Safar P, Radovsky A, Tisherman SA, Stezoski SW, Alexander $\mathrm{H}$. Delay in cooling negates the beneficial effect of mild resuscitative cerebral hypothermia after cardiac arrest in dogs: a prospective, randomized study. Crit Care Med. (1993) 21:1348-58. doi: 10.1097/00003246-199309000-00019

19. Sterz F, Safar P, Tisherman SA, Radovsky A, Kuboyama K, Oku K. Mild hypothermic cardiopulmonary resuscitation improves outcome after prolonged cardiac arrest in dogs. Crit Care Med. (1991) 19:379-89. doi: 10.1097/00003246-199103000-00017

20. Weinrauch V, Safar P, Tisherman SA, Kuboyama K, Radovsky A. Beneficial effect of mild hypothermia and detrimental effect of deep hypothermia after cardiac arrest in dogs. Stroke (1992) 23:1454-62. doi: 10.1161/01.STR.23.10.1454

21. Bernard SA, Gray TW, Buist MD, Jones BM, Silvester W, Gutteridge $\mathrm{G}$, et al. Treatment of comatose survivors of out-of-hospital cardiac arrest with induced hypothermia. N Engl J Med (2002) 346:557-63. doi: 10.1056/NEJMoa003289

22. Hypothermia After Cardiac Arrest Study Group. Mild therapeutic hypothermia to improve the neurologic outcome after cardiac arrest. N Engl J Med. (2002) 30:1756. doi: 10.1056/NEJMoa012689

23. Donnino MW, Andersen LW, Berg KM, Reynolds JC, Nolan JP, Morley, PT, et al. Temperature management after cardiac arrest an advisory statement by the advanced life support task force of the international liaison committee on resuscitation and the American Heart Association Emergency Cardiovascular Care Committee and the Council on Cardiopulmonary, Critical Care, Perioperative and Resuscitation. Circulation (2015) 132:244856. doi: 10.1161/CIR.0000000000000313

24. Testori C, Sterz F, Behringer W, Haugk M, Uray T, Zeiner A, et al. Mild therapeutic hypothermia is associated with favourable outcome in patients after cardiac arrest with non-shockable rhythms. Resuscitation (2011) 82:1162-67. doi: 10.1016/j.resuscitation.2011.05.022

25. Vaahersalo J, Hiltunen P, Tiainen M, Oksanen T, Kaukonen KM, Kurola J, et al. Therapeutic hypothermia after out-of-hospital cardiac arrest in finnish intensive care units: the finnresusci study. Intens Care Med. (2013) 39:826-37. doi: 10.1007/s00134-013-2868-1

26. Mader TJ, Nathanson BH, Soares WE, Coute RA, McNally BF. Comparative effectiveness of therapeutic hypothermia after out-of-hospital cardiac arrest: insight from a large data registry. Ther Hypothermia Temp Manag. (2014) 4:21-31. doi: 10.1089/ther.2013.0018

27. Kim YM, Yim HW, Jeong SH, Klem ML, Callaway CW. Does therapeutic hypothermia benefit adult cardiac arrest patients presenting with nonshockable initial rhythms? A systematic review and meta-analysis of randomized and non- randomized studies. Resuscitation (2012) 83:188-96. doi: 10.1016/j.resuscitation.2011.07.031

28. Nichol G, Huszti E, Kim F, Fly D, Parnia S, Donnino M, et al. Does induction of hypothermia improve outcomes after in-hospital cardiac arrest? Resuscitation (2013) 84:620-25. doi: 10.1016/j.resuscitation.2012.12.009

29. Nielsen N, Hovdenes J, Nilsson F, Rubertsson S, Stammet P, Sunde, K. et al. Outcome, timing and adverse events in therapeutic hypothermia after out-of-hospital cardiac arrest. Acta Anaesthesiol Scand. (2009) 53:926-34. doi: 10.1111/j.1399-6576.2009.02021.x

30. Huang FY, Huang BT, Wang PJ, Zuo ZL, Heng Y, Xia TL, et al. The efficacy and safety of prehospital therapeutic hypothermia in patients with out-ofhospital cardiac arrest: a systematic review and meta-analysis. Resuscitation (2015) 96:170-79. doi: 10.1016/j.resuscitation.2015.08.005

31. Kirkegaard H, Søreide E, de Haas I, Pettilä V, Taccone FS, Arus U, et al. Targeted temperature management for 48 vs 24 hours and neurologic outcome after out-of-hospital cardiac arrest: a randomized clinical trial. JAMA (2017) 318:341-50. doi: 10.1001/jama.2017.8978

32. Nielsen N, Wetterslev J, Cronberg T, Erlinge D, Gasche Y, Hassager C, et al. Targeted temperature management at $33^{\circ} \mathrm{C}$ versus $36^{\circ} \mathrm{C}$ after cardiac arrest. N Engl J Med. (2013) 369:2197-206. doi: 10.1056/NEJMoa1310519

33. Polderman KH, Herold I. Therapeutic hypothermia and controlled normothermia in the intensive care unit: practical considerations, side effects, and cooling methods. Crit Care Med. (2009) 37:1101-20. doi: 10.1097/CCM.0b013e3181962ad5
34. Seder DB, Van der Kloot TE. Methods of cooling: practical aspects of therapeutic temperature management Crit Care Med. (2009) 37(Suppl. 7):S211-22. doi: 10.1097/CCM.0b013e3181aa5bad

35. Deye N, Cariou A, Girardie P, Pichon N, Megarbane B, Midez $\mathrm{P}$, et al. Endovascular versus external targeted temperature management for patients with out-of-hospital cardiac arrest: a randomized, controlled study. Circulation (2015) 132:182-93. doi: 10.1161/CIRCULATIONAHA.114.012805

36. Glover GW, Thomas RM, Vamvakas G, Al-Subaie N, Cranshaw J, Walden A, et al. Intravascular versus surface cooling for targeted temperature management after out-of-hospital cardiac arrest-an analysis of the TTM trial data. Crit Care (2016) 20:381. doi: 10.1186/s13054-016-1552-6

37. Castrén M, Nordberg P, Svensson L, Taccone F, Vincent J, Desruelles D, et al. Intra-arrest transnasal evaporative cooling: A randomized, prehospital, multicenter study (PRINCE: Pre-ROSC IntraNasal Cooling Effectiveness). Circulation (2010) 122:729-36. doi: 10.1161/CIRCULATIONAHA.109.931691

38. Polderman KH, Noc M, Beishuizen A, Biermann H, Girbes AR, Tully GW, et al. Ultrarapid induction of hypothermia using continuous automated peritoneal lavage with ice-cold fluids: final results of the cooling for cardiac arrest or acute ST-elevation myocardial infarction trial. Crit Care Med. (2015) 43:2191-201. doi: 10.1097/CCM.0000000000001158

39. Goury A, Poirson F, Chaput U, Voicu S, Garçon P, Beeken T, et al. Targeted temperature management using the "Esophageal Cooling Device" after cardiac arrest (the COOL study): a feasibility and safety study. Resuscitation (2017) 121:54-61. doi: 10.1016/j.resuscitation.2017.09.021

40. Howes D, Gray SH, Brooks S, Boyd J, Djogovic D, Golan E, et al. Canadian guidelines for the use of targeted temperature management (Therapeutic Hypothermia) after cardiac arrest: a joint statement from The Canadian Association of Emergency Physicians (CAEP), the Canadian Critical Care Society (CCCS), Canadian Neurocritical Care Society (CNCCS), and the Canadian Critical Care Trials Group (CCCTG). Resuscitation (2016) 98:48-63. doi: 10.1016/j.resuscitation.2015. 07.052

41. Geocadin RG, Wijdicks E, Armstrong MJ, Damian M, Mayer SA, Ornato JP, et al. Practice guideline summary: reducing brain injury following cardiopulmonary resuscitation: report of the guideline development, dissemination, and implementation subcommittee of the american academy of neurology. Neurology (2017) 88:2141-9 doi: 10.1212/WNL.0000000000003966

42. Busl KM, Greer DM. Hypoxic-ischemic brain injury: pathophysiology, neuropathology and mechanisms. Neurorehabilitation (2010) 26:5-13. doi: 10.3233/NRE-2010-0531

43. Westhall E, Rossetti AO, van Rootselaar A, Kjaer TW, Horn J, Ullén S, et al. Standardized EEG interpretation accurately predicts prognosis after cardiac arrest. Neurology (2016) 86:1482-90. doi: 10.1212/WNL.0000000000002462

44. Rittenberger JC, Popescu A, Brenner RP, Guyette FX, Callaway CW. Frequency and timing of nonconvulsive status epilepticus in comatose postcardiac arrest subjects treated with hypothermia. Neurocrit Care (2012) 16:114-22. doi: 10.1007/s12028-011-9565-0

45. Mani R, Schmitt SE, Mazer M, Mutt ME, Gaieski DF. The frequency and timing of epileptiform activity on continuous electroencephalogram in comatose post-cardiac arrest syndrome patients treated with therapeutic hypothermia. Resuscitation (2012) 83:840-47. doi: 10.1016/j.resuscitation.2012.02.015

46. Monteiro ML, Taccone FS, Depondt C, Lamanna I, Gaspard N, Ligot N, et al. The prognostic value of 48 -h continuous EEG during therapeutic hypothermia after cardiac arrest. Neurocrit Care (2016) 24:152-62. doi: 10.1007/s12028-015-0215-9

47. Alvarez V, Sierra-Marcos A, Oddo M, Rossetti AO. Yield of intermittent versus continuous EEG in comatose survivors of cardiac arrest treated with hypothermia. Critical Care (2013) 17:R190. doi: 10.1186/cc12879

48. Crepeau AZ, Fugate JE, Mandrekar J, White RD, Wijdicks EF, Rabinstein $\mathrm{AA}$, et al. Value analysis of continuous EEG in patients during therapeutic hypothermia after cardiac arrest. Resuscitation (2014) 85:785-89. doi: 10.1016/j.resuscitation.2014.01.019

49. Sandroni C, Cariou A, Cavallaro F, Cronberg T, Friberg H, Hoedemaekers C, et al. Prognostication in comatose survivors of cardiac arrest: an 
advisory statement from the European Resuscitation Council and the European Society of Intensive Care Medicine. Resuscitation (2014) 85:177989. doi: 10.1016/j.resuscitation.2014.08.011

50. Crepeau AZ, Rabinstein AA, Fugate JE, Mandrekar J, Wijdicks EF, White RD, et al. Continuous EEG in therapeutic hypothermia after cardiac arrest: prognostic and clinical value. Neurology (2013) 80:339-44. doi: 10.1212/WNL.0b013e31827f089d

51. Friberg H, Westhall E, Rosén I, Rundgren M, Nielsen N, Cronberg T. Clinical review: continuous and simplified electroencephalography to monitor brain recovery after cardiac arrest. Crit Care (2013) 17:233. doi: 10.1186/cc12699

52. Synek VM. EEG abnormality grades and subdivisions of prognostic importance in traumatic and anoxic coma in adults. Clin Electroencephalogr. (1988) 19:160-66.

53. Edgren E, Hedstrand U, Nordin M, Rydin E, Ronquist G. Prediction of outcome after cardiac arrest. Crit Care Med. (1987) 15:820-25. doi: 10.1097/00003246-198709000-00004

54. Bassetti C, Bomio F, Mathis J, Hess CW. Early prognosis in coma after cardiac arrest: a prospective clinical, electrophysiological, and biochemical study of 60 patients. J Neurol Neurosurg Psychiatry. (1996) 61:610-15. doi: 10.1136/jnnp.61.6.610

55. Amirom E, Rittenberger JC, Baldwin ME, Callaway CW, Popescu A. Malignant EEG patterns in cardiac arrest patients treated with targeted temperature management who survive to hospital discharge. Resuscitation (2015) 90:127-32. doi: 10.1016/j.resuscitation.2015.03.005

56. Young GB, Doig G, Ragazzoni A. Anoxic-ischemic encephalopathy: clinical and electrophysiological associations with outcome. Neurocrit Care (2005) 2:159-64. doi: 10.1385/NCC:2:2:159

57. Zandbergen EG, Hijdra A, Koelman JH, Hart AA, Vos PE, Verbeek MM, et al. Prediction of poor outcome within the first 3 days of postanoxic coma. Neurology (2006) 10:62-8. doi: 10.1212/01.wnl.0000191308.22233.88

58. Sandroni C, Cavallaro F, Callaway CW, Sanna T, D’Arrigo S, Kuiper M, et al. Predictors of poor neurologic outcome in adult comatose survivors of cardiac arrest: a systematic review and meta-analysis. Part 1: patients not treated with therapeutic hypothermia. Resuscitation (2015) 84:1310-23. doi: 10.1016/j.resuscitation.2013.05.013

59. Berkhoff M, Donati F, Bassetti C. Postanoxic alpha (theta) coma: a reappraisal of its prognostic significance. Clin Neurophysiol. (2000) 111:297304. doi: 10.1016/S1388-2457(99)00246-1

60. Vignaendra V, Wilkus RJ, Copass MK, Chatrian GE. Electroencephalographic rhythms of alpha frequency in comatose patients after cardiopulmonary arrest. Neurology (1974) 24:582-88. doi: 10.1212/WNL.24.6.582

61. Wijdicks EF, Hijdra A, Young GB, Bassetti CL, Wiebe S, et al. Practice parameter: prediction of outcome in comatose survivors after cardiopulmonary resuscitation (an evidence-based review): report of the Quality Standards Subcommittee of the American Academy of Neurology. Neurology (2006) 67:203-10. doi: 10.1212/01.wnl.0000227183.21314.cd

62. Rossetti AO, Oddo M, Logroscino G, Kaplan PW. Prognostication after cardiac arrest and hypothermia: a prospective study. Ann Neurol. (2010) 67:301-07. doi: 10.1002/ana.21984

63. Bouwes A, van Poppelen D, Koelman JH, Kuiper MA, Zandstra DF, Weinstein HC, et al. Acute posthypoxic myoclonus after cardiopulmonary resuscitation. BMC Neurol. (2012) 12:63. doi: 10.1186/1471-2377-12-63

64. Sandroni C, Cavallaro F, Callaway CW, D’Arrigo S, Sanna T, Kuiper MA, et al. Predictors of poor neurological outcome in adult comatose survivors of cardiac arrest: a systematic review and meta-analysis. Part 2: patients treated with therapeutic hypothermia. Resuscitation (2013) 84:1324-38. doi: 10.1016/j.resuscitation.2013.06.020

65. Freund B, Kaplan PW. Myoclonus after cardiac arrest: where do we go from here? Epilepsy Curr. (2017) 17:265-72. doi: 10.5698/1535-7597.17.5.265

66. Legriel S, Hilly-Ginoux J, Resche-Rignon M, Merceron S, Pinoteau $J$, Henry-Lagarrigue $M$, et al. Prognostic value of electrographic postanoxic status epilepticus in comatose cardiac-arrest survivors in the therapeutic hypothermia era. Resuscitation (2013) 84:343-50. doi: $10.1016 /$ j.resuscitation.2012.11.001

67. Rossetti AO, Carrera E, Oddo M. Early EEG correlates of neuronal injury after brain anoxia. Neurology (2012) 78:796-802. doi: 10.1212/WNL.0b013e318249f6bb
68. Rundgren M, Westhall E, Cronberg T, Rosen I, Friberg H. Continuous amplitude-integrated electroencephalogram predicts outcome in hypothermia-treated cardiac arrest patients. Crit Care Med. (2010) 38:1838-44. doi: 10.1097/CCM.0b013e3181eaale7

69. Sivaraju A, Gilmore EJ, Wira CR, Stevens A, Rampal N, Moeller JJ, et al. Prognostication of post-cardiac arrest coma: early clinical and electroencephalographic predictors of outcome. Intens Care Med. (2015) 41:1264-72. doi: 10.1007/s00134-0153834-x

70. Ko S, Ortega-Gutierrez S, Choi HA, Claassen J, Presciutti M, Schmidt JM, et al. Status epilepticus-induced hyperemia and brain tissue hypoxia after cardiac arrest. Arch Neurol. (2011) 68:1323-6. doi: 10.1001/archneurol.2011.240

71. Herman ST, Abend NS, Bleck TP, Chapman KE, Drislane FW, Emerson RG, et al. Consensus statement on continuous EEG in critically ill adults and children, part I: indications. J Clin Neurophysiol. (2015) 32:87-95. doi: 10.1097/WNP.0000000000000166

72. Sandroni C, D’Arrigo S. Neurologic prognostication: neurologic examination and current guidelines. Semin Neurol. (2017) 37:40-47. doi: $10.1055 / \mathrm{s}-0036-1593857$

73. Westhall E, Rosén I, Rossetti AO, van Rootselaar A, Kjaer TW, Friber $\mathrm{H}$, et al. Interrater variability of EEG interpretation in comatose cardiac arrest patients. Clin Neurophysiol. (2015) 126:2397-404. doi: 10.1016/j.clinph.2015.03.017

74. Noirhomme Q, Lehembre R, Lugo ZR, Lesenfants D, Luxen A, Laureys S, et al. Automated analysis of background EEG and reactivity during therapeutic hypothermia in comatose patients after cardiac arrest. Clin EEG Neurosci. (2014) 45:6-13. doi: 10.1177/1550059413509616

75. Eveson L, Vizcaychipi M, Patil S. Role of bispectral index monitoring and burst suppression in prognostication following out-of-hospital cardiac arrest: a systematic review protocol. Syst Rev. (2017) 6:191. doi: 10.1186/s13643-017-0584-6

76. Horn J, Tjepkema-Cloostermans MC. Somatosensory evoked potentials in patients with hypoxic-ischemic brain injury. Semin Neurol. (2017) 37:60-5. doi: $10.1055 / \mathrm{s}-0036-1594252$

77. Tiainen M, Kovala TT, Takkunen OS, Roine RO. Somatosensory and brainstem auditory evoked potentials in cardiac arrest patients treated with hypothermia. Crit Care Med. (2005) 33:1736-40. doi: 10.1097/01.CCM.0000171536.63641.D9

78. Bouwes A, Binnekade JM, Zandstra DF, Koelman JH, van Schaik IN, Hijdra $A$, et al. Somatosensory evoked potentials during mild hypothermia after cardiopulmonary resuscitation. Neurology (2009) 73:1457-61. doi: 10.1212/WNL.0b013e3181bf98f4

79. Leithner C, Ploner CJ, Hasper D, Storm C. Does hypothermia influence the predictive value of bilateral absent N20 after cardiac arrest? Neurology (2010) 74:965-9. doi: 10.1212/WNL.0b013e3181d5a631

80. Zandebergen EG, Koelman JH, de Haan RJ, Hijdra A, PROPACStudy Group. SSEPs and prognosis in postanoxic coma: only short or also long latency responses? Neurology (2006) 67, 583-6. doi: 10.1212/01.wnl.0000230162.35249.7f

81. Bouwes A, Doesborg PG, Laman DM, Koelman JH, Imanse JG, Tromp SC, et al. Hypothermia after CPR prolongs conduction times of somatosensory evoked potentials. Neurocrit Care (2013) 19:25-30. doi: 10.1007/s12028-013-9856-8

82. Endisch C, Storm C, Ploner CJ, Leithner C. Amplitudes of SSEP and outcome in cardiac arrest survivors: a prospective cohort study. Neurology (2015) 85:1752-60. doi: 10.1212/WNL.0000000000002123

83. Sandroni C, D'Arrigo S, Nolan JP. Prognostication after cardiac arrest. Crit Care (2018) 22:150. doi: 10.1186/s13054-018-2060-7

84. Moseby-Knappe M, Pellis T, Dragancea I, Friberg H, Nielsen N, Horn J, et al. Head computed tomography for prognostication of poor outcome in comatose patients after cardiac arrest and targeted temperature management. Resuscitation (2017) 119:89-94. doi: 10.1016/j.resuscitation.2017.06.027

85. Mlynash M, Campbell DM, Leproust EM, Fischbein NJ, Bammer R, Eyngorn I, et al. Temporal and spatial profile of brain diffusion-weighted MRI after cardiac arrest. (2010) 41:1665-72. doi: 10.1161/STROKEAHA.110.5 82452 
86. Wijman CA, Mlynash M, Caulfield AF, Hsia AW, Eyngorn I, Bammer R, et al. Prognostic value of brain diffusion-weight imaging after cardiac arrest. Ann Neurol. (2009) 65:394-402. doi: 10.1002/ana.21632

87. Reynolds AS, Guo X, Matthews E, Brodie D, Rabbani LE, Roh DJ, et al. Post-anoxic quantitative MRI changes may predict emergence from coma and functional outcomes at discharge. Resuscitation (2017) 117:87-90. doi: 10.1016/j.resuscitation.2017.06.010

88. Hirsch KG, Mlynash M, Jansen S, Persoon S, Eyngorn I, Krasnokutsky MV, et al. Prognostic value of a qualitative brain MRI scoring system after cardiac arrest. J Neuroimaging (2014) 25:430-7. doi: 10.1111/jon.12143

89. Cronberg T, Rundgren M, Westhall E, Englund E, Siemund R, Rosén I, et al. Neuron-specific enolase correlates with other prognostic markers after cardiac arrest. Neurology (2011) 77:623-30. doi: 10.1212/WNL.0b013e31822a276d

90. Hirsch KG, Mlynash M, Eyngorn I, Pirsaheli R, Okada A, Komshian S, et al. Multi-center study of diffusion-weighted imaging in coma after cardiac arrest. Neurocrit Care (2016) 24:82-9. doi: 10.1007/s12028-015-0179-9

91. Bevers MB, Scirica BM, Avery KR, Henderson GV, Lin AP, Lee JW. Combination of clinical exam, MRI and EEG to predict outcome following cardiac arrest and targeted temperature management. Neurocrit Care (2018) doi: 10.1007/s12028-018-0559-z. [Epub ahead of print].

92. Karapetkova M, Koenig MA, Jia X. Early prognostication markers in cardiac arrest patients treated with hypothermia. Eur J Neurol. (2016) 23:476-88. doi: $10.1111 /$ ene.12803

93. Edgren E, Enblad P, Grenvik A, Lilja A, Valind S, Wiklund L, et al. Cerebral blood flow and metabolism after cardiopulmonary resuscitation. A pathophysiologic and prognostic positron emission tomography pilot study. Resuscitation (2003) 57:161-70. doi: 10.1016/S0300-9572(03)00004-2

94. Sair HI, Hannawi Y, Li S, Kornbluth J, Demertzi A, Di Perri C, et al. Early functional connectome integrity and 1-year recovery in comatose survivors of cardiac arrest. Radiology (2018) 287:247-55. doi: 10.1148/radiol.2017162161

95. Koenig MA, Holt, JL, Ernst T, Buchthal SD, Nakagawa K, Stenger VA, et al. MRI default mode network connectivity is associated with functional outcome after cardiopulmonary arrest. Neurocrit Care (2014) 20:348-57. doi: 10.1007/s12028-014-9953-3

96. Wessels T, Harrer JU, Jacke C, Janssens U, Klötzsch C. The prognostic value of early transcranial Doppler ultrasound following cardiopulmonary resuscitation. Ultrasound Med Biol. (2006) 32:1845-51. doi: 10.1016/j.ultrasmedbio.2006.06.023

97. Iida $K$, Satoh $H$, Arita K, Nakahara $T$, Kurisu K, Ohtani M. Delayed hyperemia causing intracranial hypertension after cardiopulmonary resuscitation. Crit Care Med. (1997) 25:971-76. doi: 10.1097/00003246-199706000-00013

98. Heimburger D, Durand M, Gaide-Chevronnay L, Dessertaine G, Moury PH, Bouzat P, et al. Quantitative pupillometry and transcranial Doppler measures in patients treated with hypothermia after cardiac arrest. Resuscitation (2016) 103:88-93. doi: 10.1016/j.resuscitation.2016.02.026

99. Doepp Connolly F, Reitemeier J, Storm C, Hasper D, Schreiber SJ. Duplex sonography of cerebral blood flow after cardiac arresta prospective observational study. Resuscitation (2014) 85:516-21. doi: 10.1016/j.resuscitation.2013.12.021

100. Carney N, Totten AM, O’Reilly C, Ullman JS, Hawryluk GW, Bell MJ, et al. Guidelines for the management of severe traumatic brain injury, fourth edition. Neurosurgery (2017) 80:6-15. doi: 10.1227/NEU.0000000000001432

101. Kirkman MA, Smith M. Brain oxygenation monitoring. Anesthesiol Clin. (2016) 34:537-56. doi: 10.1016/j.anclin.2016.04.007

102. Cavus E, Bein B, Dörges V, Stadlbauer KH, Wenzel V, Steinfath M, et al. Brain tissue oxygen pressure and cerebral metabolism in an animal model of cardiac arrest and cardiopulmonary resuscitation. Resuscitation (2006) 71:97-106. doi: 10.1016/j.resuscitation.2006.03.007

103. Yu J, Ramadeen A, Tsui AK, Hu X, Zou L, Wilson DF, et al. Quantitative assessment of brain microvascular and tissue oxygenation during cardiac arrest and resuscitation in pigs. Anaesthesia (2013) 68:723-35. doi: 10.1111/anae.12227

104. Friess S, Sutton HRM, French B, Bhalala U, Maltese MR, Naim $\mathrm{MY}$, et al. Hemodynamic directed CPR improves cerebral perfusion pressure and brain tissue oxygenation. Resuscitation (2014) 85:1298-303. doi: 10.1016/j.resuscitation.2014.05.040

105. Imberti R, Bellinzona G, Riccardi F, Pagani M, Langer M. Cerebral perfusion pressure and cerebral tissue oxygen tension in a patient during cardiopulmonary resuscitation. Intens Care Med. (2003) 29:1016-9. doi: $10.1007 /$ s00134-003-1719-x

106. Sanfilippo F, Serena G, Corredor C, Benedetto U, Maybauer MO, Al-Subaie $\mathrm{N}$, et al. Cerebral oximetry and return of spontaneous circulation after cardiac arrest: a systematic review and meta-analysis. Resuscitation (2015) 94:67-72. doi: 10.1016/j.resuscitation.2015.06.023

107. Ito N, Nishiyama K, Callaway CW, Orita T, Hayashida K, Arimoto H, et al. Noninvasive regional cerebral oxygen saturation for neurological prognostication of patients with out-of-hospital cardiac arrest: a prospective multicenter observational study. Resuscitation (2014) 85:778-84. doi: 10.1016/j.resuscitation.2014.02.012

108. Storm C, Leithner C, Krannich A, Wutzler A, Ploner CJ, Trenkmann L, et al. Regional cerebral oxygen saturation after cardiac arrest in 60 patients-a prospective outcome study. Resuscitation (2014) 85:1037-41. doi: 10.1016/j.resuscitation.2014.04.021

109. Sinha N, Parnia S. Monitoring the brain after cardiac arrest: a new era. Curr Neurol Neurosci Rep. (2017) 17:62. doi: 10.1007/s11910-017-0770-x

110. Ungerstedt U, Rostami E. Microdialysis in neurointensive care. Curr Pharm Des. (2004) 10:2145-52. doi: 10.2174/1381612043384105

111. Hosmann A, Schober A, Gruber A, Sterz F, Testori C, Warenits A, et al. Cerebral and peripheral metabolism to predict successful reperfusion after cardiac arrest in rats: a microdialysis study. Neurocrit Care. (2016) 24:283-93. doi: 10.1007/s12028-015-0214-x

112. Schulz MK, Wang LP, Tange M, Bjerre P. Cerebral microdialysis monitoring: determination of normal and ischemic cerebral metabolisms in patients with aneurysmal subarachnoid hemorrhage. J Neurosurg. (2000) 93:808-14. doi: 10.3171/jns.2000.93.5.0808

113. Nordmark J, Rubertsson S, Mörtberg E, Nilsson P, Enblad P. Intracerebral monitoring in comatose patients treated with hypothermia after a cardiac arrest. Acta Anaesthesiol Scand. (2009) 53:289-98. doi: 10.1111/j.1399-6576.2008.01885.x

114. Hifumi T, Kawakita K, Yoda T, Okazaki T, Kuroda Y. Association of brain metabolites with blood lactate and glucose levels with respect to neurological outcomes after out-of-hospital cardiac arrest: a preliminary microdialysis study. Resuscitation (2017) 110:26-31. doi: 10.1016/j.resuscitation.2016.10.013

115. Buunk G, van der Hoeven JG, Meinders AE. Prognostic significance of the difference between mixed venous and jugular bulb oxygen saturation in comatose patients resuscitated from a cardiac arrest. Resuscitation (1999) 41:257-62. doi: 10.1016/S0300-9572(99)00060-X

116. Takasu A, Yagi K, Ishihara S, Okada Y. Combined continuous monitoring of systemic and cerebral oxygen metabolism after cardiac arrest. Resuscitation (1995) 29:189-94. doi: 10.1016/0300-9572(94)00853-8

117. Zarzuelo R, Castañeda J. Differences in oxygen content between mixed venous blood and cerebral venous blood for outcome prediction after cardiac arrest. Intens Care Med. (1995) 21:71-5.

118. Wallin E, Larsson IM, Nordmark-Grass J, Rosenqvist I, Kristofferzon ML, Rubertsson S. Characteristics of jugular bulb oxygen saturation in patients after cardiac arrest: a prospective study. Acta Anaesthesiol Scand. (2018) 62:1237-45. doi: 10.1111/aas.13162

119. Bhatia A, Gupta AK. Neuromonitoring in the intensive care unit. I. Intracranial pressure and cerebral blood flow monitoring. Intensive Care Med. (2007) 33:1263-71. doi: 10.1007/s00134-007-0678-z

120. Reynolds AS, Matthews E, Magid-Bernstein J, Rodriguez A, Park $\mathrm{S}$, Claassen J. et al. Use of early head CT following out-ofhospital cardiopulmonary arrest. Resuscitation (2017) 113:124-7. doi: 10.1016/j.resuscitation.2016.12.018

121. Gueugniaud PY, Garcia-Darennes F, Gaussorgues P, Bancalari G, Petit P, Robert D. Prognostic significance of early intracranial and cerebral perfusion pressures in post-cardiac arrest anoxic coma. Intensive Care Med. (1991) 17:392-8. doi: 10.1007/BF01720676

122. Naito H, Isotani E, Callaway CW, Hagioka S, Morimoto N. Intracranial pressure increases during rewarming period after mild therapeutic 
hypothermia in postcardiac arrest patients. Ther Hypothermia Temp Manag. (2016) 6:189-93. doi: 10.1089/ther.2016.0009

123. International Cardiac Arrest Registry (INTCAR). International Cardiac Arrest Registry. (2012). Available online at: http://www.intcar.org/

124. ClinicalTrials.gov. Identifier NCT03261089, Multimodal Outcome CHAracterization in Comatose Cardiac Arrest Patients Registry and Tissue Repository (MOCHA). (2017). Available online at: https://clinicaltrials. gov/ct2/show/NCT03261089.

125. Cronberg T, Kuiper M. Withdrawal of life-sustaining therapy after cardiac arrest. Semin Neurol. (2017) 37:81-7. doi: 10.1055/s-0036-1595814

126. Fendler TJ, Spertus JA, Kennedy KF, Chen LM, Perman SM, Chan PS, et al. Alignment of do-not-resuscitate status with patients' likelihood of favorable neurological survival after in-hospital cardiac arrest. JAMA (2015) 314:1264-71. doi: 10.1001/jama.2015.11069
Conflict of Interest Statement: The authors declare that the research was conducted in the absence of any commercial or financial relationships that could be construed as a potential conflict of interest.

The reviewer $\mathrm{CD}$ and handling Editor declared their shared affiliation at the time of the review.

Copyright $\odot 2018$ Nguyen, Alreshaid, Poblete, Konye, Marehbian and Sung. This is an open-access article distributed under the terms of the Creative Commons Attribution License (CC BY). The use, distribution or reproduction in other forums is permitted, provided the original author(s) and the copyright owner(s) are credited and that the original publication in this journal is cited, in accordance with accepted academic practice. No use, distribution or reproduction is permitted which does not comply with these terms. 